\title{
Study on Feasibility of Sulfuric Acid Flooding in Pore-type Carbonate Reservoir
}

\author{
Bin Huang ${ }^{1,2, a}$, Wei Zhang ${ }^{2, b}$, Cheng Fu ${ }^{2, c_{\star}}$, Rui Xu ${ }^{2, d}$, Zhenzhong Shi ${ }^{2, e}$, You Lv ${ }^{2, f}$ \\ ${ }^{1}$ Beijing Deweijiaye Technology Corporation Ltd., Beijing, China,100027 \\ ${ }^{2}$ College of Petroleum Engineering, Northeast Petroleum University, Daqing, China,163318 \\ ahuangbin0201@126.com, ${ }^{\mathrm{b}} 2457124718 @ q q . c o m,{ }^{\mathrm{c}} 1852074901 @ q q . c o m,{ }^{\mathrm{d}} 609573632 @ q q . c o m$, \\ e790828189@qq.com
}

Keywords: carbonate reservoir; sulfuric acid flooding; enhanced oil recovery

\begin{abstract}
The content of carbonate in natural core was determined, the exothermic effect of sulfuric acid and water were analyzed and the increasement of core permeability due to the injection of sulfuric acid was determined. Finally, through the laboratory oil flooding test, the effect of sulfuric acid flooding was evaluated and the injection volume of sulfuric acid was optimized. The experimental results show that the effect of sulfuric acid flooding to improve oil recovery is well and the oil recovery can be increased by $7-10 \%$ based on water flooding; so we propose that injecting concentrated sulfuric acid into formation to improve oil recovery after water flooding in oil field.
\end{abstract}

\section{Introduction}

Some Russian oilfields are typical pore-type carbonate reservoir. The formation porosity and permeability is low and the crack does not develop. The whole structures are very complicated. Those reasons lead to difficulties in the exploitation of the crude oil. After a period of water flooding, the field has reached a high water cut stage now. The moisture content of the produced liquid has reached as high as $92 \%$.Low effective circulation channel has been formed in the strata. In order to extract more of the remaining oil in the strata, enhanced oil recovery measures need to be carried out after water flooding. However, the Russian oilfield strata water salinity has been up to $249.06 \mathrm{~g} / \mathrm{L}$, which limits the popularization and application of polymer, surfactant and other chemical agents.

The reaction of concentrated sulfuric acid and carbonate rocks and the fluid in the rock can enhance oil recovery effect and the nature of concentrated sulfuric acid is less affected by salinity. In this paper, aiming at an oilfield actual reservoir conditions in Russia, we carried out a feasibility study of concentrated sulfuric acid injection EOR.

\section{Experimental Conditions And Materials}

The total salinity of the simulation water used in the experiments is $249.06 \mathrm{~g} / \mathrm{L}$. The mass fraction of Sulfuric acid is 95-98\%. The simulated oil used in the experiment is composed of crude oil and kerosene which is supplied by oil field at a certain ratio .The viscosity is $9.8 \mathrm{mPa}$.s when the temperature is $30^{\circ} \mathrm{C}$. The natural core used in the experiment comes from a Russian oil field coring wells .The gas permeability is about $30 \times 10^{-3} \mu \mathrm{m}^{2}$. The physical properties of the cores used in each experiment are similar. This guarantees that the experiments have good contrast repeatability.

\section{Experimental Methods}

Content Determination of Carbonate. The carbonate content is measured based on the following reactions:

$$
\mathrm{CaCO}_{3}+2 \mathrm{HCl}=\mathrm{CaCl}_{2}+\mathrm{H}_{2} \mathrm{O}+\mathrm{CO}_{2} \uparrow
$$


Certain mass samples with dilute sulfuric acid react to produce $\mathrm{CO}_{2}$.As long as we measure the pressure after the reaction, we can calculate the carbonate content in the samples, computational formula is shown below:

$$
y=w / a=100 p v / a R T
$$

Wherein: $w$-the quality of $\mathrm{CaCO}_{3}$; $a$-the quality of rock sample, $y$-the mass fraction of carbonate in the rock samples.

Evaluation of Formation Water and Sulfuric Acid Exothermic Reaction Effect. Concentrated sulfuric acid reacting with water will emit a lot of heat. This heat can play a role in heating the oil in the strata, so as to reduce the viscosity of crude oil and improve the effect of exploitation purpose. In order to evaluate the exothermic effect of concentrated sulfuric acid reacting with water, and explore if the water salinity has an effect on exothermic. Under the same conditions, the concentrated sulfuric acid respectively will react with distilled water and the simulation water according to the proportion; we will determine and contrast the maximum temperature of the mixing liquid.

Increase Effect of Sulfuric Acid on Core Permeability. Judging from the drive mechanism of sulfuric acid, sulfuric acid and the carbonate in the strata react and generate carbon dioxide and increase the formation permeability at the same time. In this study, the injection of concentrated sulfuric acid to the core is $0.2 \mathrm{PV}$.And by measuring the permeability of the core before and after injection of sulfuric acid, we can evaluate the magnitude of core permeability improved by sulfuric acid injection.

Evaluation of Concentrated Sulfuric Acid Flooding. In order to choose the best injection parameters and to evaluate the effect of sulfuric flooding, this study was carried out with different amounts of sulfuric acid injection. The injection rate respectively is $0.1 \%, 0.2 \%$ and $0.3 \%$, and there are a total of three experimental programs.

\section{Experimental Results Analysis}

Carbonate Content in Natural Cores. Carbonate sand and hydrochloric acid react to produce $\mathrm{CO}_{2}$ to determine the carbonate content in natural sand of carbonate rocks, the results are shown in the following table.

Table.1 Results of Carbonate Content Determination

\begin{tabular}{ccccccc}
\hline Sample No. & \multicolumn{2}{c}{35} & \multicolumn{2}{c}{51} & \multicolumn{2}{c}{82} \\
Permeability [mD] & \multicolumn{2}{c}{9.49} & \multicolumn{2}{c}{29.8} & \multicolumn{2}{c}{58.1} \\
\hline Quality [g] & 0.5004 & 0.5067 & 0.5006 & 0.5091 & 0.5031 & 0.5071 \\
Pressure [kPa] & 0.538 & 0.513 & 0.552 & 0.529 & 0.512 & 0.546 \\
Mass fraction [\%] & 88.29 & 83.08 & 90.49 & 85.27 & 86.29 & 88.36
\end{tabular}

From the experimental results in the table, we can find that the content of carbonate in natural carbonate core is around $83.08 \%$-- 90.49\%, so the carbonate content of actual reservoir is high. When the carbonate content is high, after the injection of concentrated sulfuric acid, the reaction degree of strata and sulfuric acid will be relatively high.

Exothermic Effect of Sulfuric Acid and Formation Water. The results of exothermic effect are shown as follows.

Table. 2 Exothermic Effect of Sulfuric Acid Mix with Water

\begin{tabular}{cccc}
\hline Water samples & $\begin{array}{c}\text { The degree of } \\
\text { mineralization }[\mathrm{g} / \mathrm{L}]\end{array}$ & $\begin{array}{c}\text { Temperature } \\
{\left[{ }^{\circ} \mathrm{C}\right]}\end{array}$ & $\begin{array}{c}\text { Sulfuric acid/ } \\
\text { water }\end{array}$ \\
\hline Distilled water & 0 & 105 & $50 / 50$ \\
Formation water & 249.06 & 107 & $50 / 50$
\end{tabular}

The experimental results in the table show that when sulfuric acid react with the water , there would be reach above $100^{\circ} \mathrm{C}$ high temperature and heating severe, under the same conditions, the heat ( temperature ) which comes from the contact of sulfuric acid and high salinity of strata water 
and distilled water is close. The experimental results indicate that different salinity water contacting with concentrated sulfuric acid can produce a lot of heat, and salinity has nothing to do with the heat produced, under the high salinity of $249.06 \mathrm{~g} / \mathrm{L}$ in certain oilfield in Russia, the sulfuric acid can still react with strata water and generate heat, improving the development effect of the oilfield.

The Increase of Core Permeability Caused by Sulfuric Acid. The measurement results of different permeability cores before and after the injection of sulfuric acid are shown in the following table.

Table.3 Increase Range of Core Permeability Caused by Sulfuric Acid

\begin{tabular}{ccccc}
\hline $\begin{array}{c}\text { Core } \\
\text { number }\end{array}$ & $\begin{array}{c}\text { Carbonate } \\
\text { content } \\
{[\%]}\end{array}$ & $\begin{array}{c}\text { permeability before } \\
\text { acid Injection [mD] }\end{array}$ & $\begin{array}{c}\text { permeability after } \\
\text { acid Injection [mD] }\end{array}$ & $\begin{array}{c}\text { Permeability } \\
\text { value added [\%] }\end{array}$ \\
\hline 37 & 85.65 & 2.4 & 3.5 & 45.8 \\
54 & 87.56 & 29.8 & 44.3 & 48.7 \\
83 & 86.33 & 58.1 & 89.7 & 54.4 \\
\hline
\end{tabular}

The experimental results in the table show that after the injection of concentrated sulfuric acid, sulfuric acid reacts with carbonate and generates carbon dioxide, expanding the pore volume and increasing the core permeability. While the content of carbonate in the core is high, the reaction degree is great, and the added value of core permeability is about $45.8 \%--54.4 \%$. The experiment results show that when the carbonate content in carbonate reservoir is high, the reservoir permeability will have a certain increase, which is conducive to improve the development effect of oilfield.

Effect Evaluation of Sulfuric Acid Flooding. The experiment results of sulfuric acid flooding with different injection rate are shown in the following figures.

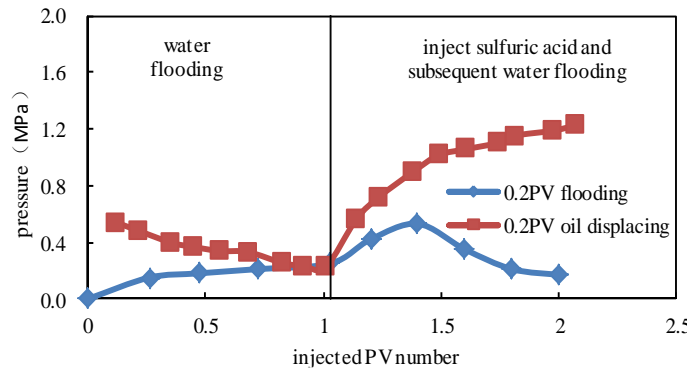

Fig 1 Injection Pressure Contrast of 0.2PV Sulfuric Acid Inject into Oil and No Oil Core

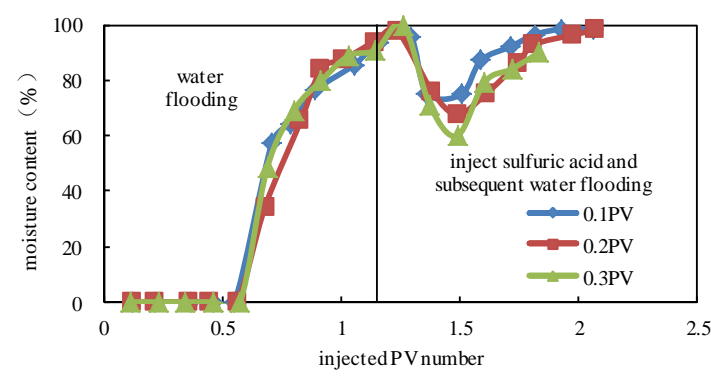

Fig. 3 Comparison of Moisture Content of Each Scheme

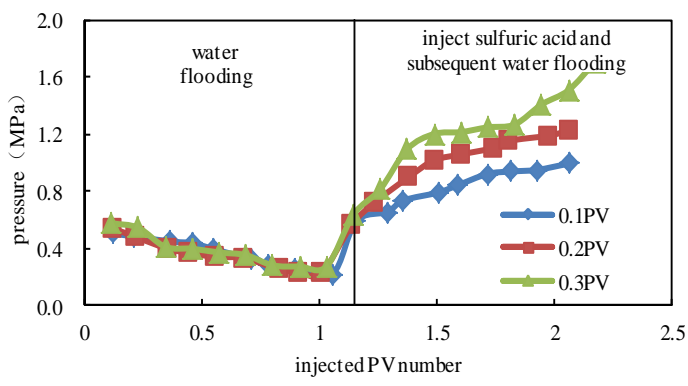

Fig 2 Injection Pressure Contrasts

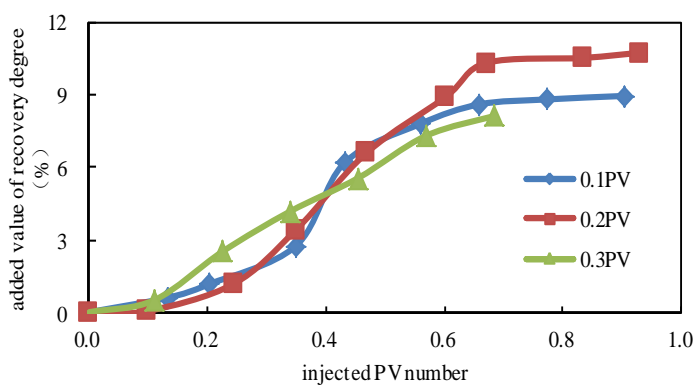

Fig.4 Increase of Recovery Degree Phase Contrast after Injecting Sulfuric Acid

From Fig. 2 we can find that the pressure increases with the injection of sulfuric acid, and the pressure continues to rise after the transfer of subsequent water flooding, indicating that after the injection of concentrated sulfuric acid, it reacts with the carbonate in the core and expands the pore 
volume, at the same time, the reaction generates lightly soluble substance $\mathrm{CaSO}_{4}$. The lightly soluble substance migrates with the fluid, which blocks part of the pore throat and leads to the increase of injection pressure.

When the injection rate of concentrated sulfuric acid increases to $0.3 \mathrm{PV}$, the sulfuric acid reacts violently with the core and generates a lot of lightly soluble substance. The blocking effect is relatively strong and the harm is great, so it is recommended to take the injection amount below $0.3 \mathrm{PV}$.

Fig. 1 show that the pressure begins to rise, and then gradually decreases when injecting the sulfuric acid into the core without oil, the change of pressure is different from the oil displacement experiment. The reasons are as follow, when there is oil in cores, the slightly soluble solid, water, oil and other multiphase flow in porous media and the flow section of each phase will become smaller compared to the core without oil. The slightly soluble substance stagnates in the narrow pore throat more easily and the core will be plugged, namely under the condition of oiliness, the slightly soluble substance which is generated by sulfuric acid and carbonate is more likely to cause harm to the core.

From the change of water content in Fig. 3 we can found that after the injection of concentrated sulfuric acid, the water content will significantly reduce. It can be seen from Fig. 4, sulfuric acid flooding can substantially increase the recovery degree of carbonate rocks, and the enhanced oil recovery value is between $8.95 \%--10.73 \%$. From the experimental results we can find that, when the injection rate is $0.2 \mathrm{PV}$, the enhanced oil recovery value is $10.73 \%$ at the stage of sulfuric acid flooding, the lowest point of water content decreases to $67.7 \%$, and the volume of slightly soluble substance is less than $0.3 \mathrm{PV}$, which does not cause serious damage to the core, so it is recommended to take the injection volume $0.2 \mathrm{PV}$.

\section{Discussion and Conclusion}

(1)The carbonate content in natural carbonate core is around $83.08 \%--90.49 \%$.

(2)When sulfuric acid contacts with the water, the temperature would reach about $100^{\circ} \mathrm{Cand}$ salinity has nothing to do with the heat produced by sulfuric acid contacting with water.

(3)After the injection of concentrated sulfuric acid, the permeability of natural core with high content of carbonate will increase by $45.8 \%--54.4 \%$.

(4)When sulfuric acid injection rate PV increased from 0.1PV to 0.2 PV Sulfuric acid flooding can increase the oil recovery effect significantly and the recovery is increased from $8.95 \%$ to $10.73 \%$. There will be serious damage to core, when injection rate is $0.3 \mathrm{PV}$ and excessive amounts of sulfuric acid and carbonate reaction will generates a large amount of gypsum. So the recommended injection rate is $0.2 \mathrm{PV}$.

(5)Overall, using the sulfuric acid flooding to improve oil recovery effect is good and can increase $7-10 \%$ based on water flooding. So it is suggested to inject sulfuric acid into strata after water flooding to improve oil recovery.

\section{Acknowledgment}

This project is financially supported by Science and Technology Research Project of Heilongjiang Province Department of Education (12541092).

\section{References}

[1] Li Dongwen, Li Xinke, Li min, etc. Experimental study of enhance oil recovery by injecting sulfuric acid [J]. Sinkiang Petroleum science and technology, 1998, 04:46-50.

[1] Li Dongwen, Li Xinke, Li min, etc. Experimental study of enhance oil recovery by injecting sulfuric acid [J]. Sinkiang Petroleum science and technology, 1998, 04:46-50. 
[2] Li Dongwen, Xu Bin, Li Xinke, etc. Experimental study of enhance oil recovery by injecting sulfuric acid II [J]. Sinkiang Petroleum science and technology, 1999, 01:30-34.

[3] Ma Shilun, Zhao Xuemeng, Guo Yujuan, etc. Enhance oil recovery by injecting sulfuric acid [J]. Foreign oilfield engineering, 1993, 01:7-9.

[4] Gao Zhenhuan, Li Caihong, Hou Qianghua, etc. Discussion of enhancing oil recovery by injecting sulfuric acid [J]. Oilfield chemistry, 1987, 01:55-57.

[5] Priyank Maheshwari, Vemuri Balakotaiah, Comparison of Carbonate HCl Acidizing Experiments with 3D Simulations, SPE PRODUCTION and OPERATIONS, 2013, Vol.28, No.4, 402-413

[6] Memon M.K., Tunio A.H., Qazi R.A., Permeability response after matrix acidizing on core plugs of lower Goru formation, Mehran University Research Journal of Engineering and Technology, 2008, Vol.27,No.4,451-462 